\title{
Effects of visual feedback training using transient Fresnel prism glasses on balance ability in stroke patients without hemispatial neglect
}

\author{
Sun-Young Ha', Su-Young Kim² ${ }^{2}$ Yun-Hee Sung ${ }^{1,2 *}$ \\ 'Department of Physical Therapy, Graduate School, Kyungnam University, Changwon, Korea \\ ${ }^{2}$ Department of Physical Therapy, Graduate School of Industry \& Business Administration, Kyungnam University, Changwon, Korea
}

The center of mass of the body in patients with stroke was oriented toward the nonparetic side. Abnormal weight shift increases the risk of falls. Therefore, many therapists make an effort to help their functional recovery through balance training. Our aim was to investigate the effect of visual feedback intervention using a Fresnel prism on static and dynamic balance in stroke patients without hemispatial neglect. Participants were assigned to control group $(n=10)$ and experimental group $(n=9)$. In the control group, neurodevelopmental therapy was performance for $30 \mathrm{~min}$. In the experimental group, Fresnel prism glasses were applied with neurodevelopmental therapy for $30 \mathrm{~min}$. We executed motor-free visual perception test for visual perception, balancia for static balance ability, and functional reach test and Berg balance test for dynamic balance ability, respectively. All tests were measured im- mediately after intervention. The visual perception function showed significant difference between unaffected side performance behaviors and visual perceptual processing time $(P<0.05)$. In the static balance, there was a significant difference in sway velocity and sway distances $(P<0.05)$. Dynamic balance was also significant different between groups $(P<0.05)$. Visual feedback using Fresnel prism helps to control the static and dynamic balance ability by inducing weight shift toward the affected side in stroke patients. Therefore, a Fresnel prism may be suggested as an intervention tool to assist weight training for patients with stroke.

Keywords: Fresnel prism, Visual feedback, Static balance, Dynamic balance, Stroke

\section{INTRODUCTION}

A stroke can occur due to damage to a part of the brain when blood vessels that supply blood to the brain get occluded or rupture. Stroke leads to the deterioration of motor and sensory functions as well as the decline in motor and sensory analysis ability, resulting in the loss of postural control, selective motor control, and balance ability (Sackley and Baguley, 1993). In particular, when the ability to control balance declines, postural sway increases such that the center of mass of the body is oriented toward the nonparetic side and approximately $80 \%$ of the total body weight shifts to the nonparetic side (Dettmann et al., 1987; Eng and Chu, 2002; Vearrier et al., 2005). The weight shift negatively affects the ability to perform activities of daily living and increases the risk of falls (Tyson et al., 2006). Therefore, improving balance ability is an important therapeutic goal in the functional recovery of stroke patients (Runge et al., 1999). The intervention methods that are used to improve the balance ability of stroke patients include weight-shifting exercises, task-specific training, constraint-induced movement therapy, robotic training, mental imaging, virtual reality training, and proprioceptive neuromuscular facilitation (Arya et al., 2011; Runge et al., 1999).

Balance refers to the ability to continuously maintain postural stability by maintaining the body's center of gravity within the base of support (BOS) by using one foot or both feet (Cohen et al., 1993). Static balance refers to the ability to maintain balance without wobbling within a fixed BOS, and dynamic balance refers to the ability to move or respond to external stimuli within the BOS
*Corresponding author: Yun-Hee Sung (iD https://orcid.org/0000-0002-4877-9784 Department of Physical Therapy, College of Health Sciences, Kyungnam University, 7 Kyungnamdaehak-ro, Masanhappo-gu, Changwon 51767, Korea

E-mail: sungpt97@kyungnam.ac.kr

Received: August 26, 2019 / Accepted: September 29, 2019
This is an Open Access article distributed under the terms of the Creative Commons Attribution Non-Commercial License (http://creativecommons.org/licenses/by-nc/4.0/) which permits unrestricted non-commercial use, distribution, and reproduction in any medium, provided the original work is properly cited. 
(Berg et al., 1992). Sensory inputs, such as inputs from the visual, somatic sensory, and vestibular systems, play an important role in maintaining balance control. These sensory inputs are essential for processing movement in space, which is associated with the position of the body, gravity, and the environment. The eyes are extensions of the brain and play a very important role in visual information processing (Melcher and Morrone, 2015).

Optical righting reactions are not only involved in spatial correlations, identification of the characteristics of objects, and distinction between objects and their backgrounds, but also provide sensory information for predictive postural control and are involved in postural changes during movement (Shumway-Cook and Woollacott, 2000; Villablanca and Olmstead, 1979). Stroke patients are generally heavily dependent on their vision because of the decline in balance ability. Although vision blocking does not necessarily lead to an inability to maintain a standing posture, postural sway does sometime occur when the eyes are closed or partially blocked (Walker et al., 2000). In addition, many previous studies have reported that vision plays a very important role in balance control (Paulus et al., 1984; Nichols, 1997).

Visual feedback training for balance control helps stroke patients become more aware of the displacement and orientation of their bodies in space (Moore and Woollacott, 1993; Yavuzer et al., 2006). In addition, it improves the accuracy of task performance by increasing selective muscle activities to help patients reduce postural sway (Madhavan and Shields, 2009). Among the several visual feedback treatments, Fresnel prisms not only offer the advantage of an expanded visual field but they also induce motor effects by aiding the conversion of the recognition of the position of objects into spatial position information while the center of the body is moving (Redding and Wallace, 2006). Visual feedback treatment using Fresnel prisms has been reported to improve the condition of stroke patients with hemispatial neglect during performing activities of daily living, such as reading, postural control, and wheelchair driving (Jacquin-Courtois et al., 2008). However, only a few studies have examined the effects of Fresnel prisms on motor control in stroke patients without hemispatial neglect. Therefore, the present study aimed to investigate the effect of visual feedback training using a Fresnel prism on the balance ability of stroke patients.

\section{MATERIALS AND METHODS}

\section{Subjects}

The study subjects included patients who were diagnosed with hemiplegia due to stroke without hemispatial neglect and who were admitted to Taebong Hospital in Gyeongsangnam-do. The subjects were recruited through bulletin boards in the hospitals. The inclusion criteria included the absence of orthopedic diseases or other diseases that might affect the study, absence of hemispatial neglect, and the ability to walk at least $10 \mathrm{~m}$ independently. We provided informed consent to subjects and the purpose and intent of the study, experimental procedures, and safety of the procedures were explained to all the study subjects before the experiment. This study followed the principles of the Declaration of Helsinki. The patients that voluntarily agreed to participate in the experiment were included in the study. The subjects were assigned to the control group ( $n=10)$ or the experimental group $(\mathrm{n}=9)$. The control group underwent neurodevelopmental intervention for 30 min while the experimental group underwent neurodevelopmental intervention by wearing prism glasses for 30 min. In the experimental group, left hemiplegia patients wore rightward-deflected prism glasses while right hemiplegia patients wore leftward-deflected prism glasses. All tests were conducted immediately after the intervention.

\section{Fresnel prism}

The Fresnel prism (Press-on, 3M Health Care, St. Paul, MN, USA) is a square ( $7.5 \mathrm{~cm}$ in length and width) transparent plastic film that has lines running across the front. The Fresnel prisms were determined to be 15 prism diopters, which was used in a previous study (Keane et al., 2006). The Fresnel prisms were cut to the size of a spectacle lens and were attached to the inside of a pair of glasses.

\section{Motor-free visual perception test}

The motor-free visual perception test (MVPT), a test that assesses a total of 36 items in 5 areas (figure-ground, visual classification, visual memory, visual completion, and spatial relations), is used to evaluate visual field deficit or visual perception of subjects. We measured the total number of answers, the number of responses behavior on the paretic side and nonparetic side, performance behavior, and visual perceptual processing time.

\section{Balance}

To measure static balance ability, each patient was requested to stand on a Wii Balance Board (Nintendo, Kyoto, Japan). Thereafter, the patient was instructed to maintain a posture with their arms lowered comfortably and focus with open eyes on a $15-\mathrm{cm}$ diameter circle drawn $3 \mathrm{~m}$ away in front of them to prevent pos- 
tural sway according to the line of vision. Measurements were started once the patient was in a stable position after standing on the Wii Balance Board and were continued for 30 sec. The Balancia software ver. 2.0 (Minto Systems, Seoul, Korea) was used to analyze the center of pressure based on the posture of the subject as previous study (Park and Lee, 2014). All the data were sampled at a $50-\mathrm{Hz}$ and $10-\mathrm{Hz}$ low-pass filter.

\section{Functional reach test}

The subjects stood next to a wall with their feet spread shoulder length apart and maintained staring posture by bending the unaffected shoulder joint forward at $90^{\circ}$ and extending the elbow joint at $0^{\circ}$. The subjects extended their arm as much as they could by bending the trunk forward without moving their feet. The tester measured the position of the end of the third metacarpal bone on the unaffected side to measure the migration distance $(\mathrm{cm})$ between the start and end points.

\section{Berg balance scale}

The Berg balance scale (BBS) is used to measure the dynamic balance ability of patients with stroke. The total score of the BBS is 56 points, and each item is scored using a 5-point scale ranging from 0 to 5 points (Berg et al., 1995).

Table 1. General characteristics of the subjects

\begin{tabular}{lccc}
\hline Variable & Control group & Experimental group & $P$-value \\
\hline Gender, male:female & $5: 4$ & $4: 6$ & \\
Paralysis, right:left & $6: 3$ & $4: 6$ & \\
Height $(\mathrm{cm})$ & $159.85 \pm 7.43$ & $164.77 \pm 8.36$ & 0.19 \\
Weight $(\mathrm{kg})$ & $55.9 \pm 12.35$ & $62.66 \pm 14.84$ & 0.29 \\
Age $(\mathrm{yr})$ & $57.10 \pm 7.17$ & $52.55 \pm 17.27$ & 0.45 \\
Duration $(\mathrm{mo})$ & $6.60 \pm 1.42$ & $8.44 \pm 5.74$ & 0.37 \\
\hline
\end{tabular}

Values are presented as mean \pm standard deviation.

Table 2. The change of visual perception after visual feedback training

\begin{tabular}{lccc}
\hline Variable & $\begin{array}{c}\text { Control } \\
\text { group }\end{array}$ & $\begin{array}{c}\text { Experimental } \\
\text { group }\end{array}$ & P-value \\
\hline Affected side response behavior (score) & $18.10 \pm 5.46$ & $15.44 \pm 4.18$ & 0.24 \\
Unaffected side response behavior (score) & $17.90 \pm 5.46$ & $18.55 \pm 5.47$ & 0.79 \\
$\begin{array}{l}\text { Affected side performance behavior (score) } \\
\text { Unaffected side performance behavior }\end{array}$ & $14.80 \pm 2.78$ & $14.33 \pm 4.06$ & 0.77 \\
$\quad$ (score) & $9.90 \pm 4.06$ & $14.22 \pm 5.67$ & $0.03^{*}$ \\
Raw score (score) & $24.90 \pm 4.06$ & $28.22 \pm 5.99$ & 0.18 \\
\hline
\end{tabular}

Values are presented as mean \pm standard deviation.

${ }^{*} P<0.05$.

\section{Data analysis}

Statistical analysis was performed using IBM SPSS Statistics ver. 21.0 (IBM Co., Armonk, NY, USA). The results are presented as the mean \pm standard deviation. The Shapiro-Wilk test was used to verify the normality. Independent sample $t$-tests were conducted to compare the data between the groups, and the statistical significance was set at $P<0.05$.

\section{RESULTS}

\section{General characteristics}

No significant differences in height, weight, age, or disease duration were observed between the two groups $(P<0.05)$ (Table 1$)$.

\section{Visual perception skill}

In the MVPT, and significant differences were observed between the control group and the experimental group with regard to the performance behavior of the unaffected side performance and visual perceptual processing time $(P<0.05)$. However, no other significant differences were observed between the two groups $(P<$ 0.05) (Table 2).

\section{Static balance ability}

In the static balance ability, significant differences were observed between the control and experimental group with regard to sway velocity and sway distances $(P<0.05)$, but no significant differences were observed with regard to sway area $(P<0.05)$ (Table 3$)$.

\section{Dynamic balance ability}

In the dynamic balance ability, significant differences were ob-

Table 3. The change of static balance after visual feedback training

\begin{tabular}{lccc}
\hline Variable & Control group & Experimental group & $P$-value \\
\hline Velocity $(\mathrm{cm} / \mathrm{sec})$ & $5.25 \pm 1.57$ & $3.83 \pm 0.91$ & $0.03^{*}$ \\
Path Length $(\mathrm{cm})$ & $78.79 \pm 23.62$ & $57.56 \pm 13.73$ & $0.02^{*}$ \\
Path/Area95 $\left(\mathrm{cm}^{2}\right)$ & $7.76 \pm 6.41$ & $10.29 \pm 4.94$ & 0.23 \\
\hline
\end{tabular}

Values are presented as mean \pm standard deviation.

${ }^{*} P<0.05$.

Table 4. The change of dynamic balance after visual feedback training

\begin{tabular}{lccc}
\hline Variable & Control group & Experimental group & $P$-value \\
\hline BBS $($ score $)$ & $31.20 \pm 6.16$ & $44.22 \pm 7.25$ & $0.00^{*}$ \\
FRT $(\mathrm{cm})$ & $4.64 \pm 2.63$ & $14.81 \pm 6.54$ & $0.00^{*}$ \\
\hline
\end{tabular}

Values are presented as mean \pm standard deviation. $\mathrm{BBS}$, Berg balance scale; FRT, functional reaching test. ${ }^{*} P<0.05$. 
served between the control group and the experimental group in the BBS and functional reach test (FRT), respectively $(P<0.05)$ (Table 4).

\section{DISCUSSION}

Fresnel prisms changes the perceptual information that comes into the retina into spatial information, and the continuous stimulus by it moves the body center by inducing the adaptation effect. It accomplishes the effect of shifting the visual field in specific directions. Thus, the use of Fresnel prisms can lead to an increase in movement toward spaces on paretic side in stroke patients (Keane et al., 2006; Redding and Wallace, 2006). The MVPT was used to assess whether the stroke patients experienced vision issues when wearing the Fresnel prism glasses. In the unaffected side performance behavior item, there was significant difference, however, in the rest of the items, no significant differences were observed between the groups. This indicates that Fresnel prism glasses helps to extend the visual field to the unaffected side, but do not affect the overall visual perception performance ability of the patients.

Visual feedback intervention helps improve balance control in stroke patients (Geiger et al., 2001). Laufer et al. (2000) reported a close correlation between visual information and weight shifts toward the affected side in acute phase patients. They also found that visual feedback balance training was more effective than conventional treatments for weight shifts. Visual feedback balance training improved standing posture stability and gait ability in patients with hemiplegia due to stroke (Hamman et al., 1992; Shumway-Cook et al., 1988). However, some studies have reported that treadmill-walking treatment combined with visual feedback training was not effective in improving balance in stroke patients (Yang et al., 2011). In addition, Van Peppen et al. (2006) reported that postural training, which involves the use of visual feedback to move the center of gravity during standing, may not be adequately effective. In this study, we found that visual feedback treatment using Fresnel prisms has resulted in a natural weight shift to the unaffected side, thereby affecting the sway velocity and distance of the paretic side and the nonparetic side to maintain static balance.

If the body is moved quickly when the center of body has been stabilized on the BOS, a new BOS will be created and static balance is changed into a system to maintain dynamic balance ability (Pai and Patton, 1997). Most activities of daily living require postural control ability that is achieved with dynamic balance ability rather than static balance ability. Therefore, improvement of dynamic balance ability after controlling static balance ability is critical for patients with central nervous system damage and for those who have poor balance control ability that prevents them from independently performing activities of daily living (Flynn et al., 2007). Visual feedback training helps stroke patients identify body movements and spatial orientation through visual information, thereby helping them improve their postural control ability (Dault et al., 2003; de Haart et al., 2004; Jeong and Oh, 2013). Balance training along with visual feedback training exhibited greater improvements in lower extremity motor ability and dynamic balance than general physical therapy (Kligyte et al., 2003; Walker et al., 2000). In the present study, the patients who wore prism glasses exhibited significantly greater improvement in dynamic balance than did the control group in the BBS test. The results of the FRT also indicated that the patients in the experimental group could reach approximately $10 \mathrm{~cm}$ more than did the control group patients. This indicates that the Fresnel prisms help dynamic balance and a lower risk of falls (Bogle Thorbahn and Newton, 1996).

Our findings demonstrated that the visual feedback produced by the Fresnel prisms induced the weight shift on the affected side and movements toward the affected side such that new bases of support were formed, thereby affecting balance maintenance and control. However, this study findings cannot be generalized because the number of study subjects was small and the interventions were provided only once. Therefore, long-term intervention studies are required to determine the treatment effect duration. In addition, the effects of the use of diverse prism angles are yet to be determined.

\section{CONFLICT OF INTEREST}

No potential conflict of interest relevant to this article was reported.

\section{REFERENCES}

Arya KN, Pandian S, Verma R, Garg RK. Movement therapy induced neural reorganization and motor recovery in stroke: a review. J Bodyw Mov Ther 2011;15:528-537.

Berg K, Wood-Dauphinee S, Williams JI. The Balance Scale: reliability assessment with elderly residents and patients with an acute stroke. Scand J Rehabil Med 1995;27:27-36.

Berg KO, Maki BE, Williams JI, Holliday PJ, Wood-Dauphinee SL. Clini- 
cal and laboratory measures of postural balance in an elderly population. Arch Phys Med Rehabil 1992;73:1073-1080.

Bogle Thorbahn LD, Newton RA. Use of the Berg Balance Test to predict falls in elderly persons. Phys Ther 1996;76:576-583.

Cohen H, Blatchly CA, Gombash LL. A study of the clinical test of sensory interaction and balance. Phys Ther 1993;73:346-351.

Dault MC, de Haart M, Geurts AC, Arts IM, Nienhuis B. Effects of visual center of pressure feedback on postural control in young and elderly healthy adults and in stroke patients. Hum Mov Sci 2003;22:221-236.

de Haart M, Geurts AC, Huidekoper SC, Fasotti L, van Limbeek J. Recovery of standing balance in postacute stroke patients: a rehabilitation cohort study. Arch Phys Med Rehabil 2004;85:886-895.

Dettmann MA, Linder MT, Sepic SB. Relationships among walking performance, postural stability, and functional assessments of the hemiplegic patient. Am J Phys Med 1987;66:77-90.

Eng JJ, Chu KS. Reliability and comparison of weight-bearing ability during standing tasks for individuals with chronic stroke. Arch Phys Med Rehabil 2002;83:1138-1144.

Flynn S, Palma P, Bender A. Feasibility of using the Sony PlayStation 2 gaming platform for an individual poststroke: a case report. J Neurol Phys Ther 2007;31:180-189.

Geiger RA, Allen JB, O'Keefe J, Hicks RR. Balance and mobility following stroke: effects of physical therapy interventions with and without biofeedback/forceplate training. Phys Ther 2001;81:995-1005.

Hamman RG, Mekjavic I, Mallinson AI, Longridge NS. Training effects during repeated therapy sessions of balance training using visual feedback. Arch Phys Med Rehabil 1992;73:738-744.

Jacquin-Courtois S, Rode G, Pisella L, Boisson D, Rossetti Y. Wheel-chair driving improvement following visuo-manual prism adaptation. Cortex 2008;44:90-96.

Jeong MK, Oh DW. Effects of 12-week balance training with visual feedback on balance and walking functions in patients with chronic stroke. J Digit Converg 2013;11:537-544.

Keane S, Turner C, Sherrington C, Beard JR. Use of fresnel prism glasses to treat stroke patients with hemispatial neglect. Arch Phys Med Rehabil 2006;87:1668-1672.

Kligyte I, Lundy-Ekman L, Medeiros JM. Relationship between lower extremity muscle strength and dynamic balance in people post-stroke. Medicina (Kaunas) 2003;39:122-128.

Laufer Y, Dickstein R, Resnik S, Marcovitz E. Weight-bearing shifts of hemiparetic and healthy adults upon stepping on stairs of various heights. Clin Rehabil 2000;14:125-129.

Madhavan S, Shields RK. Movement accuracy changes muscle-activation strategies in female subjects during a novel single-leg weight-bearing task. PM R 2009;1:319-328.
Melcher D, Morrone MC. Nonretinotopic visual processing in the brain. Vis Neurosci 2015;32:E017.

Moore S, Woollacott MH. The use of biofeedback devices to improve postural stability. Phys Ther Practice 1993;2:1-19.

Nichols DS. Balance retraining after stroke using force platform biofeedback. Phys Ther 1997;77:553-558.

Pai YC, Patton J. Center of mass velocity-position predictions for balance control. J Biomech 1997;30:347-354.

Park DS, Lee G. Validity and reliability of balance assessment software using the Nintendo Wii balance board: usability and validation. J Neuroeng Rehabil 2014;11:99.

Paulus WM, Straube A, Brandt T. Visual stabilization of posture. Physiological stimulus characteristics and clinical aspects. Brain 1984;107(Pt 4):1143-1163.

Redding GM, Wallace B. Prism adaptation and unilateral neglect: review and analysis. Neuropsychologia 2006;44:1-20.

Runge CF, Shupert CL, Horak FB, Zajac FE. Ankle and hip postural strategies defined by joint torques. Gait Posture 1999;10:161-170.

Sackley CM, Baguley BI. Visual feedback after stroke with the balance performance monitor: two single-case studies. Clin Rehabil 1993;7: 189-195.

Shumway-Cook A, Anson D, Haller S. Postural sway biofeedback: its effect on reestablishing stance stability in hemiplegic patients. Arch Phys Med Rehabil 1988;69:395-400.

Shumway-Cook A, Woollacott M. Attentional demands and postural control: the effect of sensory context. J Gerontol A Biol Sci Med Sci 2000; 55:M10-16.

Tyson SF, Hanley M, Chillala J, Selley A, Tallis RC. Balance disability after stroke. Phys Ther 2006;86:30-38.

Van Peppen RP, Kortsmit M, Lindeman E, Kwakkel G. Effects of visual feedback therapy on postural control in bilateral standing after stroke: a systematic review. J Rehabil Med 2006;38:3-9.

Vearrier LA, Langan J, Shumway-Cook A, Woollacott M. An intensive massed practice approach to retraining balance post-stroke. Gait Posture 2005;22:154-163.

Villablanca JR, Olmstead CE. Neurological development of kittens. Dev Psychobiol 1979;12:101-127.

Walker C, Brouwer BJ, Culham EG. Use of visual feedback in retraining balance following acute stroke. Phys Ther 2000;80:886-895.

Yang S, Hwang WH, Tsai YC, Liu FK, Hsieh LF, Chern JS. Improving balance skills in patients who had stroke through virtual reality treadmill training. Am J Phys Med Rehabil 2011;90:969-978.

Yavuzer G, Eser F, Karakus D, Karaoglan B, Stam HJ. The effects of balance training on gait late after stroke: a randomized controlled trial. Clin Rehabil 2006;20:960-969. 